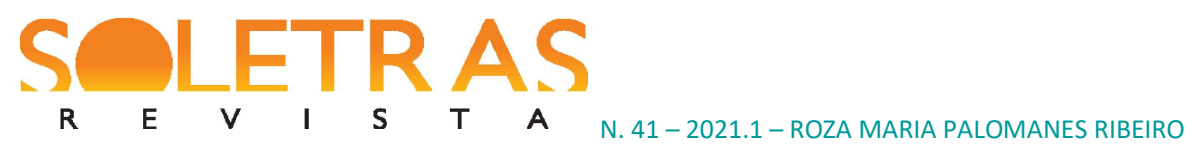

\title{
A metaftonímia presente na construção $X$ virar Uber
}

\author{
Roza Maria Palomanes Ribeiro ${ }^{1}$
}

\begin{abstract}
Resumo: O presente artigo tem como objeto de estudo a construção $X$ virar Uber. O fenômeno da uberização, crescente no Brasil, que levou desempregados a se cadastrarem como motoristas do aplicativo administrado pela empresa $U B E R$, resultou no surgimento da construção em estudo, frequente na fala do brasileiro. O propósito da pesquisa é descrever a construção sob o viés teórico da Linguística Cognitiva, mais especificamente no que tange aos processamentos metafórico e metonímico (LAKOFF; JOHNSON, 2002; RADDEN; KÖVECSES, 2007; LAKOFF; TURNER,1989; CROFT, 1993; GOOSSENS, 2002), partindo da hipótese de que o fenômeno da metaftonímia está presente na sua construção de sentido. Para tanto, coletaram-se dados através da ferramenta de buscas GOOGLE, levando-se em conta as 100 primeiras ocorrências distribuídas nas 10 primeiras páginas de busca, optando-se por um tratamento qualitativo dos dados. Após seleção e análise dos dados coletados, chegase à conclusão de que ocorre, neste caso estudado, o fenômeno da metaftonímia do tipo metáfora da metonímia, em que a entidade conceptual Empresa Uber provê acesso mental à entidade conceptual motorista de aplicativo, dentro do mesmo domínio, configurando o processo metonímico. E, ao mesmo tempo, se dá um mapeamento entre domínios da experiência sustentados pela metáfora O HOMEM É UMA ENTIDADE NÃO HUMANA. Espera-se, com a pesquisa, contribuir para os estudos sobre metaftonímia.
\end{abstract}

Palavras-chave: Metáfora. Metonímia. Metaftonímia.

\section{Palavras iniciais}

A forma como moldamos o mundo está diretamente ligada à questão dos sentidos e do significado, que não pode ser visto simplesmente como um reflexo do que acontece ao nosso redor. Novas experiências e mudanças em nosso meio requerem a adaptação de categorias semânticas a transformações e circunstâncias, e entendemos que esses significados construídos na língua não se separam em um módulo independente da mente, mas refletem nossas experiências de uma maneira geral como seres humanos. Sendo assim, podemos dizer que o significado linguístico não pode ser separado de outros tipos de conhecimento de mundo que compartilhamos, ou seja, nosso conhecimento de mundo está integrado a outras capacidades.

Dito isso, cabe acrescentar que, uma vez que nossa natureza orgânica influencia nossa experiência com o mundo, tal natureza tende a se refletir nos usos da língua, embora não

\footnotetext{
${ }^{1}$ Mestre e Doutora em Linguística pela UFRJ. Professor associado de Linguística da UFRRJ. Experiência de mais de 25 anos no ensino básico. Coautora dos livros Manual de Linguística e Práticas de Ensino do Português pela Ed. Contexto. Brasil. E-mail: rozapalomanes@terra.com.br. ORCID iD: https://orcid.org/0000-0001-8618-2922
} 


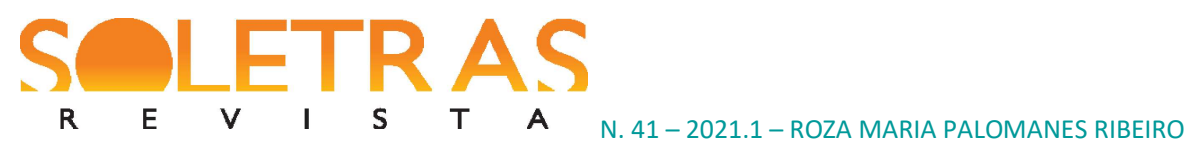

sejamos apenas seres biológicos, pois temos uma identidade cultural e social, e as línguas incorporam as experiências culturais e históricas.

A Linguística Cognitiva, dentre outros pressupostos, entende o conhecimento em conexão com as experiências de mundo do ser. Este entendimento permite que as unidades e as estruturas da linguagem sejam estudadas como manifestações de capacidades cognitivas gerais, da organização conceptual, de princípios de categorização, de mecanismos de processamento e da experiência cultural, social e individual.

Assim posto, tendo por base teórica os pressupostos trazidos pela Linguística Cognitiva, o presente artigo tem como objetivo principal descrever os processos metafóricos e metonímicos subjacentes à construção X VIROU $\mathrm{UBER}^{2}$, usada com muita frequência no Brasil, a partir do fenômeno de uberização. Tal fenômeno cresceu em todas as cidades brasileiras em face da alta taxa de desemprego que levou pessoas a se cadastrarem como motoristas do aplicativo administrado pela empresa UBER. Como já mencionado, novas experiências e mudanças em nosso meio requerem a adaptação de categorias semânticas, o que motiva a presente pesquisa. A análise pretendida se apoia particularmente nos estudos desenvolvidos Lakoff e Johnson (2002), Radden e Kövecses, (2007), Lakoff e Turner (1989), Croft (1993) e Goossens (2002).

Entendendo, como Lakoff e Johnson (2002), que nosso sistema conceptual desempenha papel central em definir nossa realidade cotidiana, sendo esse amplamente metafórico de forma que a maneira como pensamos, o que experienciamos e o que fazemos cotidianamente é uma questão de metáfora, pretende-se responder, neste artigo, às seguintes questões: Que processos cognitivos, além da metáfora, atuam na construção de sentido da estrutura analisada? De que forma?

Para tanto, coletaram-se dados através da ferramenta de buscas GOOGLE, levando-se em conta as 100 primeiras ocorrências distribuídas nas 10 primeiras páginas de busca apresentadas, a fim de observar a frequência de uso da construção e os contextos em que é utilizada. Embora busquemos considerar o uso da construção para certificar que se trata de uma estrutura muito comum na fala cotidiana do brasileiro, a opção metodológica foi por um tratamento fundamentalmente qualitativo por entender que atende melhor à proposta da

\footnotetext{
${ }^{2}$ UBER é uma empresa multinacional americana, prestadora de serviços eletrônicos na área do transporte privado urbano, através de um aplicativo de transporte que permite a busca por motoristas baseada na localização. (https://pt.wikipedia.org/wiki/Uber)
} 


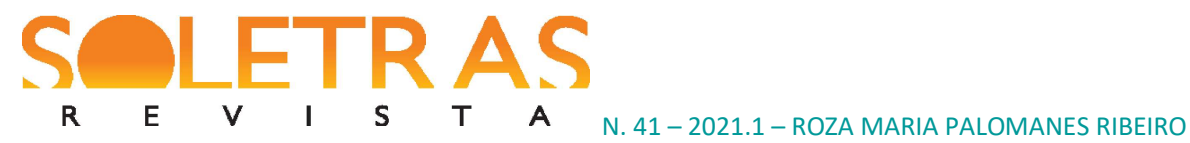

pesquisa e porque o que se busca é descrever e compreender o fenômeno, respeitando o objetivo traçado, as orientações teóricas adotadas e o comportamento dos dados selecionados e observar os processos cognitivos que atuam na construção de sentido da estrutura analisada.

Este artigo encontra-se dividido em cinco seções que se seguem. Na primeira, dedicamo-nos a apresentar os pressupostos teóricos da Linguística Cognitiva que sustentam a pesquisa aqui apresentada. $\mathrm{Na}$ segunda seção, trataremos dos processamentos cognitivos metáfora e metonímia da forma como são estudados por autores como Lakoff e Johnson (2002), Radden e Kövecses, (2007), Lakoff e Turner (1989), Croft (1993) e Goossens (2002). A seção três apresenta a metaftonímia tratada, primeiramente, por Goossens (2002), fenômeno importante para o presente estudo. Na quarta seção, são apresentadas as análises da construção estudada e, por fim, na quinta seção, tecemos as considerações finais.

\section{Embasando a discussão: o aparato teórico}

O surgimento da Linguística Cognitiva (doravante LC), no final do século XX, foi visto como a renovação do interesse por se estudar a conceptualização da realidade pela língua, uma vez que é uma abordagem da linguagem que vê o conhecimento em conexão com as experiências de mundo do ser. Geeraerts (2006) conceitua a LC como um arquipélago formado por várias ilhas teóricas, mas que estão estreitamente unidas pela forma de estudar as unidades e as estruturas da linguagem como manifestações de capacidades cognitivas gerais, da organização conceptual, de princípios de categorização, de mecanismos de processamento e da experiência cultural, social e individual.

Negando a tese da autonomia da linguagem, a LC opõe-se às teorias formalistas. Pela importância que atribui aos aspectos funcionais dos fenômenos linguísticos, e por desenvolver uma análise linguística com base na observação da língua em uso, a LC é um tipo de linguística pragmaticamente orientada, tanto teórica como metodologicamente.

Para a LC, as categorias gramaticais são, como as lexicais, entidades simbólicas, isto é, significativas (simbolizam um conteúdo conceptual), estando intimamente relacionadas com a categorização, processos imagéticos, modelos cognitivos e culturais. 


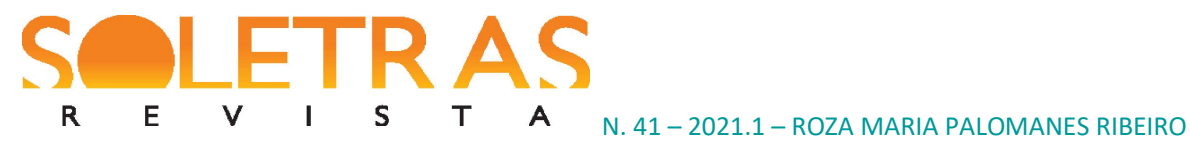

A LC caracteriza-se, ainda no quadro da ciência cognitiva, pela importância que atribui à semântica na análise linguística. A primazia da semântica decorre da própria perspectiva cognitiva: a linguagem funciona como um dispositivo cognitivo para a construção do conhecimento, acionando um conjunto de princípios relativamente limitados, que operam sobre os conhecimentos armazenados na memória ou presentes na situação comunicativa. Surge daí um de seus princípios centrais que é o caráter enciclopédico do significado das palavras (c.f. Langacker 1987). Embora, em teoria, todo o conhecimento sobre uma entidade esteja acessível, parte desse conhecimento é mais central e o padrão de centralidade e periferia é uma parte importante daquilo que distingue o significado de uma palavra da outra.

Entender o significado de uma palavra na visão cognitivista de conhecimento enciclopédico implica acessar a rede de conhecimento mais central, ativando-a em um determinado ponto ou pontos. Segundo Langacker:

The entity designated by a symbolic unit can therefore be thought of as a point of access to a network. The semantic value of a symbolic unit is given by the openendedset of relations ... in which this access node participates. Each of theserelations is a cognitive routine, and because they share at least one component theactivation of one routine facilitates (but does not always necessitate) the activation of another ${ }^{3}$. (LANGACKER, 1987, p. 163)

Lakoff e Johnson definem a posição filosófica e epistemológica da LC como sendo o experiencialismo (cf. Lakoff e Johnson 2002, Lakoff 1987, Johnson 1987). Isto pode ser explicado da seguinte forma: a cognição é determinada pela própria experiência corporal do homem e pela experiência individual e coletiva. Também se diz que a LC é paradigmática no sentido de que assinala que a interpretação e a aquisição de novas experiências são feitas à luz de conceitos e categorias já existentes, que, por isso mesmo, funcionam como paradigmas ou protótipos.

\footnotetext{
${ }^{3}$ A entidade designada por uma unidade simbólica pode, portanto, ser vista como um ponto de acesso a uma rede. O valor semântico de uma unidade simbólica é dado pelo conjunto aberto de relações ... no qual esse nó de acesso participa. Cada uma dessas relações é uma rotina cognitiva e, por compartilharem pelo menos um componente, a ativação de uma rotina facilita (mas nem sempre exige) a ativação de outra. (LANGACKER, 1987, p. 163)
} 


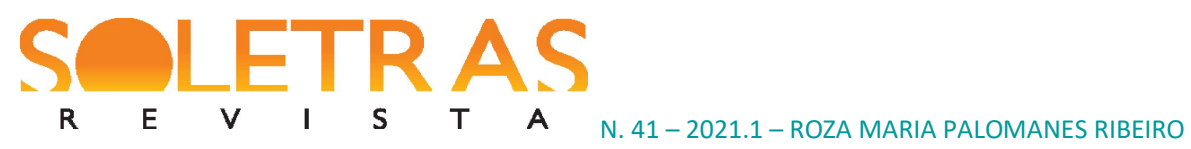

Importante destacar que, para Lakoff e Johnson (1999): (a) a mente é inerentemente corporificada; (b) o pensamento é quase totalmente inconsciente e (c) conceitos abstratos são amplamente metafóricos. Segundo os referidos autores, o homem usa a razão moldada pelo corpo, uma inconsciência cognitiva à qual não se tem acesso direto e um pensamento metafórico do qual se é amplamente inconsciente, sendo o pensamento abstrato quase que totalmente metafórico.

Dentro dessa perspectiva, a língua não é pura sintaxe, pura forma, independente de todo significado, contexto, percepção, emoção, memória, atenção, ação e da dinâmica natureza da comunicação. Aspectos centrais da linguagem brotam evolucionariamente do sensório, do motor e de outros sistemas neurais presentes no homem. Assim, as categorias gramaticais são entidades simbólicas, isto é, significativas (simbolizam um conteúdo conceptual). Elas devem, portanto, ser consideradas não somente em termos das suas propriedades sintáticas, mas tendo em conta a sua base semântica.

Visto que a metáfora e a metonímia são fundamentais para a descrição e análise pretendidas, na próxima seção serão apresentados esses conceitos dentro do paradigma cognitivista.

\section{A Metáfora e a Metonímia como processos cognitivos}

A Teoria da Metáfora Conceptual, de Lakoff e Jonhson (2002), apresenta a metáfora como um processamento cognitivo intimamente relacionado à experiência humana cotidiana, isto é, a metáfora, assim como a metonímia, fazem parte do pensamento humano, se baseiam na experiência sensório-motora e estruturam nosso pensamento e ações. Lakoff (2006) afirma que a metáfora - ou mapeamento entre domínios - é central à semântica das línguas naturais em seu dia a dia. Segundo o autor, o uso da metáfora em textos literários é uma extensão dos estudos da metáfora cotidiana. Para Lakoff:

o que constitui a metáfora não é nenhuma palavra ou expressão em particular. É, sim, o mapeamento ontológico que atravessa domínios conceptuais, de um domínio-fonte [...] para um domínio alvo [...]. A metáfora não é apenas uma questão de linguagem, mas de pensamento e de razão. A língua é secundária. O mapeamento é primário. O mapeamento é convencional, isso quer dizer que 


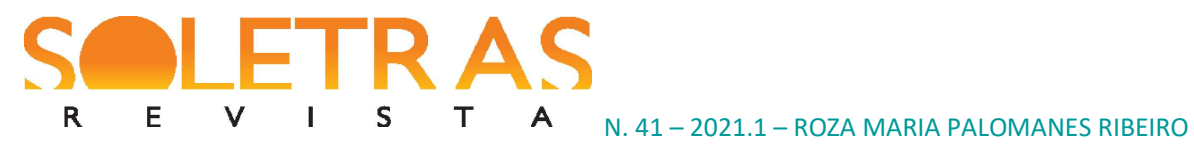

ele é uma parte fixa do nosso sistema conceptual [...]Se metáforas fossem meramente expressões linguísticas, nós esperaríamos que as expressões linguísticas diferentes fossem metáforas diferentes. (LAKOFF, 1993, p. 209).

A metáfora é, pois, concebida como um mecanismo cognitivo de conceptualização que torna possível significar o mundo em que se vive. O cerne da metáfora conceptual é experienciar alguma coisa em termos de outra e expressar, por meio da linguagem, o que é compreendido via experiência corpórea. A noção de domínio, portanto, desempenha papel crucial para que se compreendam situações mais abstratas, como experiências emocionais e culturais. A partir de um domínio-fonte, que é mais próximo da experiência humana física, concreta e bem conhecida, compreende-se um domínio alvo, mais próximo das experiências humanas emocionais, psíquicas, sendo, por consequência, mais abstrato e pouco conhecido. Como afirma Lakoff (1987, p. 288), "(...) metaphoric mapping involves a source domain and a target domain. ... The mapping is typically partial. It maps the structure in the source domain onto a corresponding structure in the target domain". ${ }^{4}$

O entendimento da metáfora como primariamente conceitual, convencional e parte do sistema comum de pensamento e linguagem (c.f Lakoff, 2006, p.186) foi primeiro apresentado por Reddy (1993). De acordo com seu ensaio A metáfora do conduto, foi possível perceber como a língua inglesa comum do cotidiano era amplamente metafórica. Conforme Lakoff (2006, p. 187), Reddy teria sido o primeiro a demonstrar, através de rigorosa análise linguística, que a metáfora é um processo cognitivo comum, usada cotidianamente.

Essa forma de se entender a metáfora permitiu estudos sobre metáforas conceptuais convencionais, impulsionados pelo próprio Reddy (1993), Lakoff e Turner (1989) e outros. Lakoff (2006), ao estudar a metáfora conceptual de algumas expressões cotidianas do inglês, como, por exemplo, as que se baseiam na conceptualização do AMOR COMO UMA VIAGEM, levantou as seguintes questões: Há um princípio geral regendo tais expressões que dá conta de como se relaciona viagem a amor? Há um princípio geral atuando em padrões de inferência que permitem relacionar viagem a amor?

Para Lakoff (2006), existe um princípio geral único que responde tanto pela polissemia quanto pela inferência. Esse princípio geral faz parte do sistema conceptual subjacente ao

\footnotetext{
4 “O mapeamento metafórico envolve um domínio-fonte e um domínio-alvo. ... O mapeamento é tipicamente parcial. Mapeia a estruturano domínio-fonte em uma estrutura correspondente no domínio-alvo.” (tradução nossa).
} 


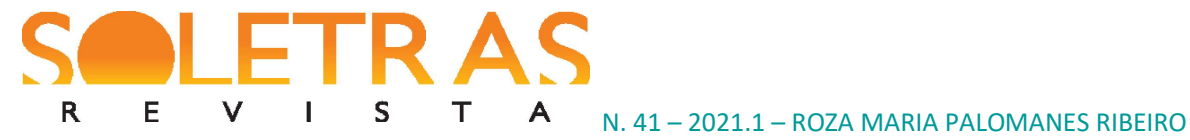

inglês, que permite que se entenda o domínio do amor em termos do domínio da viagem. Tal princípio pode ser compreendido, de maneira informal, como um cenário metafórico:

The lovers are travelers on a journey together, with their common life goals seen as destinations to be reached. The relationship is their vehicle, and it allows them to pursue those common goals together. The relationship is seen as fulfilling its purpose as long as it allows them to make progress toward their common goals. The journey isn't easy. There are impediments, and there are places (crossroads) where a decision has to be made about which direction to go in and whether to keep traveling together. ${ }^{5}$ (LAKOFF, 2006, p. 190)

Por entender a metáfora como um mapeamento entre domínios da experiência, em AMOR É UMA VIAGEM (LAKOFF, 2006), tal mapeamento é possível por haver possibilidades de correspondência entre as entidades que constituem os domínios: no domíniofonte, tem-se as entidades viajantes, veículo e destino, que podem ser relacionadas às entidades do domínio-alvo, amantes, relacionamento e objetivos do casal. O que permite a metáfora AMOR É UMA VIAGEM não é, somente, uma palavra ou expressão isolada. Para Lakoff:

It is the ontological mapping across conceptual domains, from the source domain of journeys to the target domain of love. The metaphor is not just a matter of language, but of thought and reason. The language is secondary. The mapping is primary, in that it sanctions the use of source domain language and inference patterns for target domain concepts. The mapping is conventional, that is, it is a fixed part of our conceptual system, one of our conventional ways of conceptualizing love relationships. ${ }^{6}$ (LAKOFF, 2006, p. 192)

\footnotetext{
${ }^{5}$ Os amantes são viajantes em uma jornada juntos, com seus objetivos de vida comuns vistos como destinos a serem alcançados. O relacionamento é o veículo deles e permite que eles persigam esses objetivos comuns juntos. O relacionamento é visto como cumprindo seu objetivo, desde que permita que eles progridam em direção a seus objetivos comuns. A jornada não é fácil. Existem impedimentos e existem lugares (encruzilhadas) onde é necessário tomar uma decisão sobre qual direção seguir e se devem continuar viajando juntos. (LAKOFF, 2006, p.190, tradução nossa)

${ }^{6}$ É o mapeamento ontológico entre domínios conceituais, do domínio de origem das viagens ao domínio de destino do amor. A metáfora não é apenas uma questão de linguagem, mas de pensamento e razão. O idioma é secundário. O mapeamento é primário, na medida em que sanciona o uso da linguagem do domínio de origem e padrões de inferência para conceitos de domínio de destino. O mapeamento é convencional, ou seja, é uma parte fixa de nosso sistema conceitual, uma das formas convencionais de conceituar relacionamentos amorosos. (LAKOFF, 2006, p.192, tradução nossa)
} 


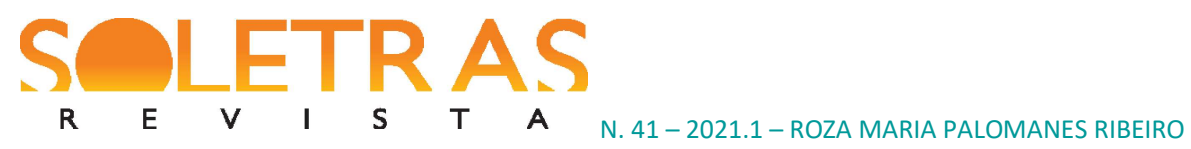

Com relação à metonímia, há estudos (c.f. Lakoff e Johnson, 2002 e Lakoff e Turner, 1989) segundo os quais a metonímia constitui, assim como a metáfora, um processo cognitivo, mais que algo puramente linguístico, por meio do qual há um deslocamento de significado. Ou seja, um termo linguístico que, em geral, é utilizado para designar dada entidade passa a designar um ser com a qual tenha uma relação de contiguidade, por exemplo. É através da metonímia que se realizam mapeamentos em um mesmo domínio, tornando possível o estabelecimento de conexões entre dimensões de um domínio conceptual.

Como bem afirmam Lakoff e Johnson (2002), metáfora e metonímia são processos cognitivos de natureza diferente, embora a metonímia, assim como a metáfora, estruture nossos pensamentos, atitudes e ações, sendo os conceitos metonímicos, tal como os metafóricos, fundamentados em nossa experiência. A metáfora é, como já dito anteriormente, um modo de conceber uma coisa em termos de outra, sendo sua função primordial a compreensão. A metonímia, no entanto, permite que se use uma entidade para representar outra, acumulando, assim, função referencial e de compreensão. Para Lakoff e Johnson (2002), a metonímia tem o mesmo uso da metáfora, mas é mais óbvia pelas associações fisicas ou causais diretas que proporciona; a metonímia permite que se focalizem mais especificamente certos aspectos de dada entidade. Metonímia e metáfora não são, somente, uma questão de linguagem: são parte de como o homem age, pensa e fala no seu dia a dia.

Radden e Kövecses (2007) também estudam os processos cognitivos da metáfora e metonímia e entendem que a visão cognitiva da metonímia parte de três diferentes assunções:

(a) a metonímia é um fenômeno conceptual;

(b) a metonímia é um processo cognitivo;

(c) a metonímia opera dentro de um MCI (modelo cognitivo idealizado)

Resumindo, trata-se de um processo cognitivo em que uma entidade conceptual provê um acesso mental a outra entidade conceptual, dentro do mesmo domínio.

Sendo assim, para fins de análise da construção em estudo, entendemos a metonímia como um fenômeno conceptual cujo uso é um reflexo de metonímias conceptuais mais gerais, um "fenômeno de transferência referencial baseado na contiguidade espaço-temporal, tal como é concebido pelo falante entre uma entidade e outra no mundo real" (SETO, 1999, p.91 tradução nossa). 


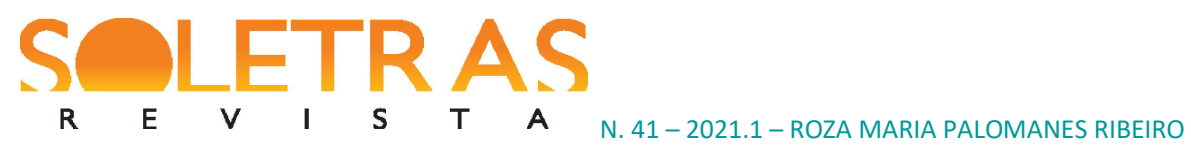

Ruiz de Mendoza (2000) distingue dois tipos básicos de metonímia, a saber: alvo-emfonte e fonte-em-alvo. O primeiro tipo se refere ao caso em que o domínio-matriz representa um de seus subdomínios e o segundo tipo ocorre quando um subdomínio representa o domíniomatriz correspondente. Como exemplos respectivos têm-se (1) Ela está tomando pílula (se referindo a pílulas anticonceptivas - exemplo de Ruiz de Mendoza, 2000, p.113) e (2) Você pode me dar uma mão aqui (se referindo a uma ajuda no trabalho - exemplo nosso).

A diferença entre os processos cognitivos metáfora e metonímia estaria no fato de que a projeção metonímica envolve um único domínio enquanto a projeção metafórica envolve dois. Lakoff e Turner (1989), em contribuições posteriores, propõem que há projeção entre domínios no processo metonímico, desde que estes se caracterizem como subdomínios de um mesmo domínio-matriz, o que exemplifica Mendoza (2000) citado no parágrafo anterior.

Há pesquisas na literatura cognitivista que defendem a ideia de haver uma relação simbiótica entre metáfora e metonímia nomeada de metaftonímia. Goossens (2002) trata do fenômeno da metaftonímia em que, em expressões linguísticas nas quais se percebe a origem metonímica, é possível perceber, também, correspondência metafórica. Esse fenômeno será melhor apresentado na próxima seção.

\section{A Metaftonímia}

Goossens (2002) foi o primeiro a defender uma interação entre a metáfora conceptual e a metonímia conceptual de modo a propor o termo metaftonímia. Segundo o autor, há situações em que o que originalmente é uma metonímia passa por uma metaforização, como é o caso de expressões como "bater cabeça" em "Margarida e Joana limparam a mesma janela e não limparam as demais; têm que combinar antes para não ficarem batendo cabeça”, quando se refere a um atrapalhar o outro em algum trabalho. Para Goossens (2002), pode haver (a) metáfora da metonímia; (b) metonímia dentro de uma metáfora (meter o pé no sentido de ir embora, por exemplo); (c) desmetonimização dentro de uma metáfora e (d) metáfora dentro da metonímia quando se usa a metáfora para dar mais expressividade à metonímia.

Goossens (2002) sugere que as metaftonímias são de dois tipos básicos, a saber: metaftonímia integrada e metaftonímia cumulativa. A metaftonímia integrada é aquela em que 


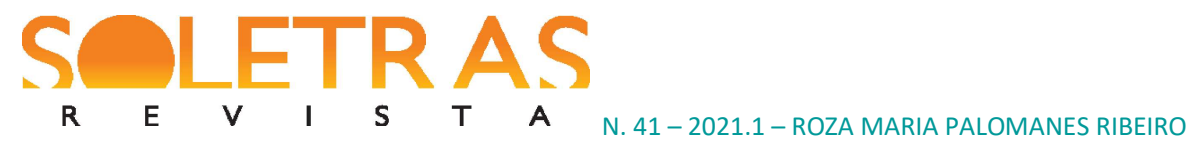

na mesma expressão há uma metáfora e uma metonímia combinadas. Nessa categoria, Goossens (2002) inclui os casos de metonímia dentro da metáfora e metáfora dentro da metonímia. Quanto à metaftonímia cumulativa, para o referido autor, é aquela que implica que uma metáfora é derivada de uma metonímia ou vice-versa. São os casos em que há metáforas a partir de uma metonímia e metonímia a partir de uma metáfora.

Goossens (2002) afirma, ainda, que existem dois padrões atuais para a interação de metáfora e metonímia:

(a) caso em que a base experiencial para a metáfora é uma metonímia, produzindo o que ele chama de metáfora da metonímia;

(b) caso em que o funcionamento metonímico no domínio-alvo está incorporado a uma metáfora, i.e., metonímia dentro da metáfora.

Ainda segundo Goossens (2002), os outros tipos de metaftonímia são muito mais difíceis de conceituar sendo, portanto, casos excepcionais.

Entende-se que os exemplos da metaftonímia de Goossens (2002) são, essencialmente, desenvolvimentos metonímicos de uma fonte metafórica situacional. No entanto, autores como Ruiz de Mendoza e Díez (2002) afirmam que há outras maneiras nas quais a metáfora e a metonímia interagem:

Basically, metonymy is subsidiary to -and thus part of- metaphor. Since there are two basic metonymic schemas: part-for-whole (source-in-target) and whole-for-part (target-in-source), this yields four basic interactional patterns:

(i) Metonymic expansion of a metaphoric source

(ii) Metonymic reduction of a metaphoric source

(iii) Metonymic expansion of a metaphoric target

(iv) Metonymic reduction of a metaphoric target (RUIZ DE MENDOZA E DÍEZ, 2002, p.10) ${ }^{7}$

\footnotetext{
${ }^{7}$ Basicamente, a metonímia é subsidiária e, portanto, parte da metáfora. Como existem dois esquemas metonímicos básicos: parte por todo (fonte emdestino) e todo para peça (destino na fonte), isso gera quatro interações básicas padrões:

(i) Expansão metonímica de uma fonte metafórica

(ii) Redução metonímica de uma fonte metafórica

(iii) Expansão metonímica de um alvo metafórico

(iv) Redução metonímica de um alvo metafórico (RUIZ DE MENDOZA E DÍEZ, 2002, p.10, tradução nossa)
} 
Esses padrões citados foram, originalmente, propostos e discutidos em Ruiz de Mendoza (1997) e, em seguida, em Ruiz de Mendoza e Díez (2002), sendo aplicados em estudos de caso recentes no contexto da multimodalidade.

\section{Estudo do corpus: descrição da construção}

A construção X virar UBER, objeto de estudo da presente pesquisa, se insere no rol das construções resultativas do português por apontar uma mudança de estado, possuindo um argumento semântico extra, o sintagma resultativo (SR), que indica o estado resultante de uma situação provocativa anterior, que pode vir ou não vir na mesma cláusula.

Sabe-se, pelos estudos realizados por Goldberg (1995), que a construção resultativa é uma extensão metafórica da construção de movimento causado associada à semântica $x$ causa y mover-se a $z$. Porém, neste estudo, pretende-se analisar tal construção, com base no estudo de Goossens (2002), que aponta quatro possíveis interações entre metáfora e metonímia em construções gramaticais resultando no processo de metaftonímia. Goossens (2002, p. 356) analisa o exemplo "Oh dear," shegiggled, "I'd quite forgotten." como um caso em que há uma interpretação metafórica (ela disse o que disse como se estivesse rindo), com um vínculo conceitual com a leitura metonímica presente. É o que ele chama de metaphor from metonymy (metáfora da metonímia), como representado no esquema a seguir:

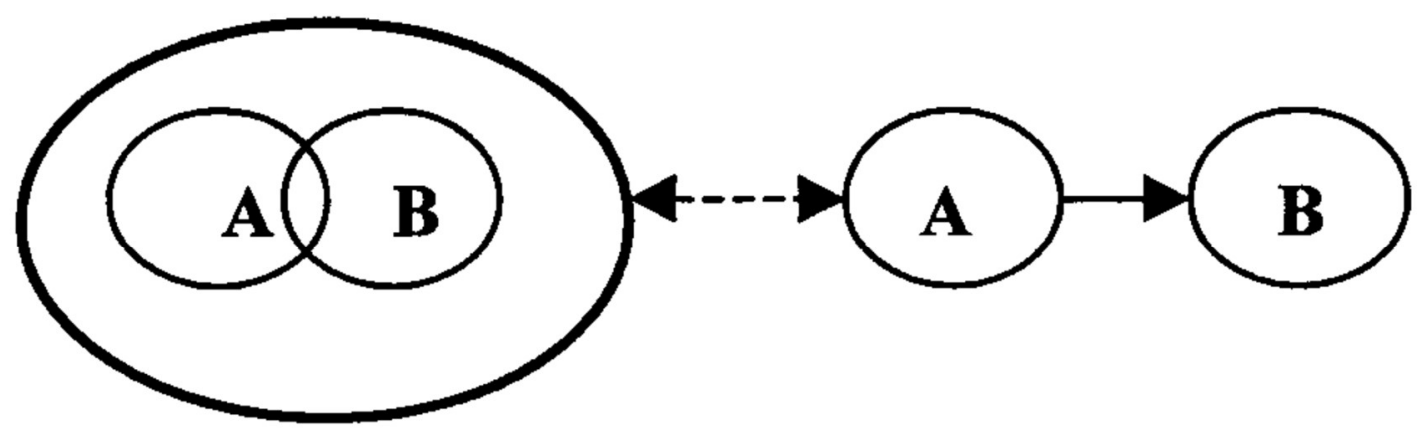

Esquema 1: metáfora da metonímia

Fonte: Goossens (2002, p.357) 


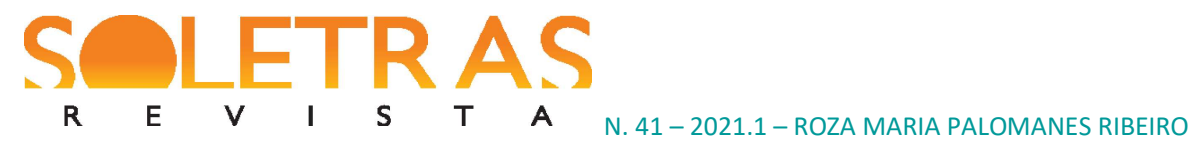

Goossens assim explica o esquema: no lado esquerdo da imagem, dois domínios A e B se cruzam e são fundidos em uma única cena (a área circundante ao círculo). No lado direito, A e B são separados, mas, como a seta indica, resta um vínculo conceitual com a cena em que os dois estão juntos.

A partir do que propõe Goossens (2002), defende-se que, na construção de sentido da estrutura analisada neste artigo, ocorre um mapeamento de um domínio-fonte a um domínioalvo, a partir da metonímia o instrumento/serviço pelo utilizador, como pode ser visto no esquema a seguir:
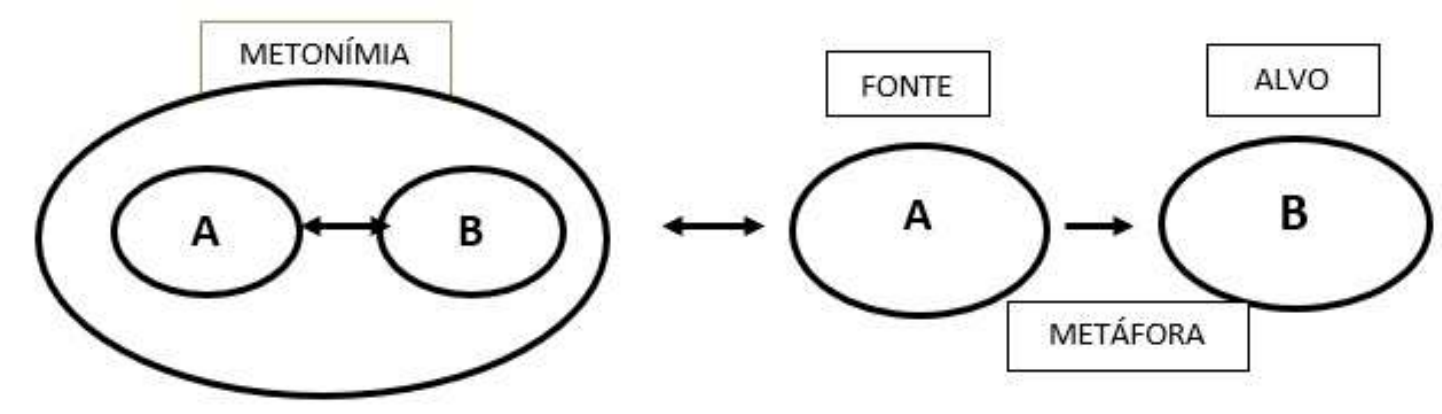

Esquema 2: Esquema conceptual da construção de sentido de $\mathrm{X}$ virar Uber.

Fonte: o pesquisador

O esquema 2, inspirado em Goossens (2002, p.357), representa o processo de metaftonímia pelo qual é submetida a construção X virar Uber. À esquerda da imagem, ilustrase o processo metonímico em que há um deslocamento de significado: entidade A passa a designar um ser (entidade B) com a qual tem uma relação de contiguidade, ou seja, a entidade conceptual UBER provê acesso mental a outra entidade conceptual MOTORISTA QUE USA O APLICATIVO DA UBER. A ilustração leva em conta, também, que a metonímia opera dentro de um MCI. A partir daí, dá-se a metáfora da metonímia: via metáfora O HOMEM É UMA EMPRESA é que se transfere do domínio-fonte para o domínio-alvo a ideia de alguém que exerce a atividade desenvolvida pela empresa UBER. Assim, a construção passa a ser amplamente utilizada, sem causar estranheza ou dificuldades de interpretação pelo falante comum. Observemos alguns dados selecionados com a construção em estudo:

(1) Jornalista virou Uber por um mês e lucrou só 30 reais por dia. ${ }^{8}$

\footnotetext{
${ }^{8}$ https://vejasp.abril.com.br/cidades/uber-teste-motorista-um-mes 


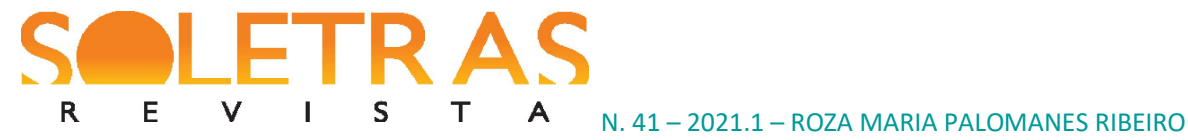

(2) Dione virou Uber há aproximadamente dois meses, após perder o emprego. "E aí comecei a ganhar muitas gorjetas por causa do meu atendimento."9

Em (1) e (2), é possível perceber que é dentro do modelo cognitivo do esquema serviço/utilizado que o processamento metonímico se dá. A construção (1) é metonimicamente compreendida no sentido de ter o jornalista exercido a função de motorista do aplicativo administrado pela empresa UBER. Esse alvo metonímico forma parte de um modelo idealizado em nossa cultura. Segundo Lakoff (1987), os MCIs permitem distinguir figura e fundo. Não se dá uma simples soma de significados individuais. Na verdade, o MCI é um todo estruturado complexo em que se elegem variadas perspectivas para uma dada situação. Voltando aos exemplos (1) e (2), a partir do espaço metonímico criado, há um mapeamento de um domíniofonte a um domínio-alvo (metáfora) em que o jornalista e Dione são vistos como a própria atividade desempenhada pela empresa UBER. Tal mapeamento se apoia na metáfora ontológica EMPRESA É UMA PESSOA/ O HOMEM É UMA EMPRESA.

Analisemos outros exemplos com a construção X virar Uber:

(3) Muita gente virou Uber no Brasil, mas esse é um mundo bem distante do glamour. A agência pública fez reportagem com um ex-jornalista que não consegue fugir da sensação de fracasso após ter virado motorista de aplicativo. ${ }^{10}$

(4) Atacante virou Uber após calote de time paraibano. ${ }^{11}$

(5) Alexandre Frota virou uber por estar sem emprego na TV? ${ }^{12}$

(6) O vereador que virou Uber: A corrida de Uber era curta, do escritório ao centro da cidade. Ao abrir a porta do carro, a surpresa: no volante, Tonhão Dutra. ${ }^{13}$

Nos exemplos de (3) a (6), observa-se, aplicando-se o esquema 2, o qual considera a metaftonímia do tipo metáfora da metonímia, que a entidade conceptual Empresa Uber provê um acesso mental à entidade conceptual motorista de aplicativo, dentro do mesmo domínio, configurando o processo cognitivo metonímia. Ao mesmo tempo, ocorre o mapeamento entre domínios da experiência (metáfora), uma vez que há correspondência entre as entidades que

\footnotetext{
${ }^{9}$ https://www.brasildefatomg.com.br/2019/12/20/motorista-de-bh-incentiva-passageiros-a-interagirem-com-ostrabalhadores-da-rua

${ }^{10} \mathrm{https}: / /$ www.facebook.com/169590426398017/posts/2519028044787565/

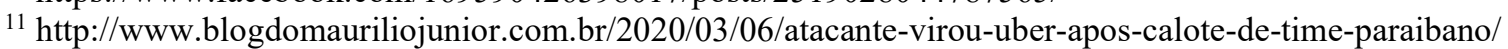

$12 \mathrm{https} / / / \mathrm{www}$.e-farsas.com/alexandre-frota-virou-uber-por-estar-sem-emprego-na-tv.html

${ }^{13} \mathrm{http}$ ://www.blogdoispontos.com/2017/11/o-vereador-que-virou-uber.html
} 


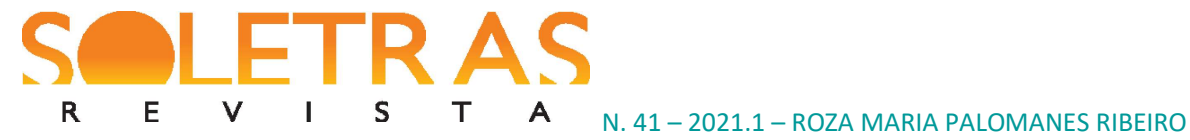

constituem os domínios: no domínio-fonte, tem-se uma empresa que pode ser relacionada à entidade do domínio-alvo funcionário/trabalhador/motorista. O que permite a metáfora presente na construção de sentido da estrutura estudada não é, somente, uma palavra ou expressão isolada, como demonstra Lakoff (2006, p.192) ao dizer que a "metáfora não é apenas uma questão de linguagem, mas de pensamento e razão. O idioma é secundário. O mapeamento é primário, na medida em que sanciona o uso da linguagem do domínio de origem e padrões de inferência para conceitos de domínio de destino". (tradução nossa).

Encerra-se, assim, a seção referente à descrição da construção X VIRAR UBER em que puderam ser percebidos os processos metafóricos e metonímicos subjacentes à estrutura analisada, além da interação entre metáfora e metonímia, o que permite a proposição de estarmos diante de um caso de metaftonímia.

\section{Considerações finais}

Com base no que foi apresentado, levando-se em conta o objetivo principal doartigo, que é descrever os processos metafóricos e metonímicos subjacentes à construção X VIRAR UBER segundo os pressupostos teóricos da Linguística Cognitiva, particularmente os estudos desenvolvidos por Lakoff e Johnson (2002), Radden e Kövecses, (2007), Lakoff e Turner (1989), Croft (1993) e Goossens (2002), chegamos à seguinte conclusão: a metaftonímia está presente na construção de sentido de $X$ virar Uber. Pôde-se perceber, através da análise dos dados selecionados, que a construção passa por um processo metonímico em que há um deslocamento de significado de uma entidade a outra (instrumento/serviço pelo utilizador) com a qual tem uma relação de contiguidade, operando dentro de um mesmo domínio. A partir desse ponto, ocorre o que Goossens (2002) chama de metáfora da metonímia. É via metáfora $\mathrm{O}$ HOMEM É UMA EMPRESA que se compreende a ideia de que o termo Uber se refere, na verdade, a uma pessoa que exerce a atividade desenvolvida pela empresa mencionada.

Considera-se que as questões da pesquisa foram respondidas quando se demonstrou, na seção referente à descrição, quais processos cognitivos atuam na construção de sentido da estrutura analisada e de que maneira isso se dá. 


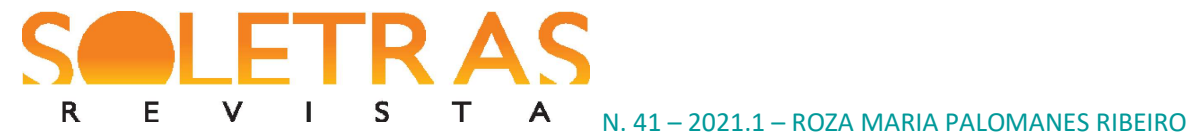

Desta forma, cumpre-se o propósito do presente artigo, oferecendo uma descrição da construção X VIRAR UBER, observando-se questões relativas ao seu processamento com destaque para a metaftonímia.

Espera-se, assim, ter contribuído para os estudos sobre metaftonímia por acreditar que casos como o estudado, com uma origem metonímica e uma correspondência metafórica, sejam numerosos na fala do brasileiro. Com isso, deseja-se que novas pesquisas sobre o fenômeno sejam incentivadas.

\section{Referências}

CROFT, W. The role of domains in the interpretation of metaphors and metonymies. Cognitive Linguistics, 4(4), p. 335-370, 1993.

GEERAERTS, D. (org.). Cognitive Linguistics: Basic Readings. Berlin/New York: Mouton de Gruyter, 2006.

GOOSSENS, L. Metaphtonymy: the interaction of metaphor and metonymy in expressions for linguistic action. Cognitive Linguistics, 1 (3), p. 323-340, 2002.

JOHNSON, M. The body in the mind. the bodily basis of meaning, imagination, and reason. Chicago: Chicago University Press, 1987.

LAKOFF, G. Women, fire and dangerous things. What Categories reveal about the Mind. Chicago: University of Chicago Press, 1987.

. Conceptual metaphor: the contemporary theory of metaphor. In: GEERAERTS, Dirk. Cognitive Linguistics: basic readings. Berlim: 2006. p. 185-238.

LAKOFF, G.; JOHNSON, M. Philosophy in the flesh: The embodied mind and its challenge to Western though. New York: Basic Books, 1999.

Metáforas da vida cotidiana. Coord. de tradução de Mara Zanotto. Campinas: Mercadão das Letras, 2002.

; TURNER, M. More than cool reason: a field guide to poetic metaphor. Chicago: The University of Chicago Press, 1989.

LANGACKER, R. W. Foundations of cognitive grammar. Volume 1: Theoretical Prerequisites. Stanford: Stanford University Press, 1987. 
RADDEN, G.; KÖVECSES Z. Towards a theory of metonomy. In: EVANS, V.; BERGEN, B.; ZINKEN. J. (org.). The Cognitive Linguistics Reader. London: Equinox, 2007, p. 335-359.

REDDY, Michael J. The conduit metaphor: a case of frame conflict in our language about language. in: Ortony, Andrew (ed.). Metaphor and Thought, Cambridge, 1993, p. 164-201.

RUIZ DE MENDOZA IBÁÑEZ, Francisco J. Cognitive and pragmatic aspects of metonymy. Cuadernos de Filología, Universidad de Murcia, 1997, Vol.6, p.161-178.

; Francisco J. The role of mappings and domains in understanding metonymy. Metaphor and Metonymy at the Crossroads: a Cognitive Perspective, ed by Antonio Barcelona, 109-132. Berlin \& New York: Mouton, 2000, p.97-118.

; O. DÍEZ. Patterns of Conceptual Interaction. Metaphor and Metonymy in Comparison and Contrast. Eds. R. Dirvenand R. Pörings. Berlin/New York: Mouton de Gruyter, 2002, p. 489-532.

SETO, K. Distinguishing metonymy from synecdoche. In: K.U. Panther and G. Radden, eds. Metonymy in language and thought. Amsterdam: John Benjamins, 1999, p. 91-120.

\title{
Metaphtonymy in the construction $\mathrm{X}$ became Uber
}

\begin{abstract}
This article aims to study the construction X become Uber. The phenomenon of uberization, which is growing in Brazil, has led unemployed people to register as drivers of the application managed by the company UBER. With this, the construction object of study becomes frequent in the Brazilian's speech. The purpose of the research is to analyze the construction under the theoretical bias of Cognitive Linguistics, more specifically with regard to metaphorical and metonymic processing (LAKOFF; JOHNSON, 2002; RADDEN; KÖVECSES, 2007; LAKOFF; TURNER, 1989; CROFT, 1993; GOOSSENS, 2002). For that, data were collected through the search tool GOOGLE taking into account the first 100 occurrences distributed in 10 search pages presented, opting for a qualitative treatment of the data. After selecting and analyzing the data, it is concluded that, in this case, the metaphor phenomenon of the metaphor metonymy type occurs, in which the conceptual entity Uber Company provides mental access to the conceptual entity application driver, within the same domain, configuring the metonymic process. And, at the same time, there is a mapping between domains of experience supported by the metaphor MAN IS A NON-HUMAN ENTITY. It is expected, with the research, to contribute to studies on metaphtonymy.
\end{abstract}

Keywords: Metaphor. Metonym. Metaphtonymy.

Recebido em: 21 de julho de 2020.

Aceito em: 17 de dezembro de 2020. 